\title{
What PEEP level should I use in my patient?
}

\section{Federico Gordo Vidal (1 y 2) \\ Isabel Conejo Marquez (1)}

(1) Servicio de Medicina Intensiva. Hospital Universitario del Henares (CosladaMadrid)

\section{(2) Universidad Francisco de Vitoria (Madrid)}

What PEEP level should I use in my patient?, this is a question we ask ourselves everyday in clinical practice when we are dealing with mechanical ventilation in the intensive care unit (ICU).

Nowadays this question doesn't have a unique answer, which causes an important variability in clinical practice. Recent studies in patients with ARDS (Acute respiratory distress syndrome) present this variability as well as non-compliance of clinical practice guidelines recomendations. For example, in LUNG-SAFE (1) study only $53 \%$ of ARDS patients were ventilated with tidal volume less than $7 \mathrm{ml} / \mathrm{kg}$ while PEEP level used in these patients, with fraction of inspired oxygen (FiO2) greater than $70 \%$, was even lower than the recomendations of low PEEP level group in ALVEOLI study (2). This argument regarding PEEP level is not exclusive for patients with ARDS but this parameter is controversial in other situations such as surgical patients or patients with exacerbations of chronic obstructive pulmonary disease (COPD), both to set FiO2 and to improve patient-ventilator interaction (3).

It is demonstrated that the use of lung protective ventilation strategies improve the outcome of patients with ARDS and there is broad consensus in using a limited tidal volume and a limited lung pressure, as well as using PEEP levels higher than those used (and still being used) in routine clinical practice $(4,5)$. However, there is no consensus regarding the appropriate strategy to select a PEEP level in each patient, so that different strategies are used with different purposes, what, at the moment, could be the two basic strategies: optimal PEEP determination depending on pulmonary mechanics of each patient or PEEP level adjustment depending on the quotient $\mathrm{PaO} 2 / \mathrm{FiO} 2$ (6).

Recently, we have learned that in order to set tidal volumen and PEEP level we have to keep in mind hemodynamics and pulmonary mechanics monitorization in patients with ARDS, so what is important to set ventilatory parameters is knowing lung recruitment capacity (to avoid atelectrauma) and keep the balance with an adequate tidal volumen (to avoid overstretching phenomena). Undoubtedly, adequate balance between lung recruitment and overstretching improves not only lung function but also cardiac function in patients with ARDS.

In a meta-analysis conducted by our group analyzing the effect of high PEEP versus conventional PEEP in ARDS (7), we have already described that the use of high PEEP 
was not associated to increase mortality. However, if we consider only those studies in which high PEEP level is selected depending on the pulmonary mechanics characteristics, obtained by performing pressure-volume curves, the use of a high PEEP level was associated with a significant reduction in mortality (RR $0.59,95 \% \mathrm{Cl}$ 0.43 to 0.82 ) and the incidence of barotrauma (RR $0.24,95 \% \mathrm{Cl} 0.09$ to 0.70 ).

Recently Amaro et al (10) have published the Driving Pressure Concept. Driving pressure could be the most important force in mechanical ventilation, it is the ratio as an index indicating the "functional" size of the lung an would provide a better predictor of outcomes in patients with ARDS than volume tidal alone. This ratio $(\triangle P=$ Volume tidal/static Compliance), can be routinely calculated for patients who are not making inspiratory efforts as the plateau pressure minus PEEP (10).

Pintado et all. (8) published a randomized study comparing a lung protective ventilation strategy with two types of setting PEEP level in 70 patients with ARDS: based on $\mathrm{PaO} 2 / \mathrm{FiO} 2$ or based on pulmonary mechanics, searching for the best pulmonary compliance point. Main results have shown the group selected based on compliance had more organ dysfunction-free days (median 6 vs. 20,5 days; $P=0,02$ ), more days without respiratory failure (7,5 vs. 14,5 days; $P=0,03)$, and more days without hemodynamic failure ( 16 vs. 22 days; $P=0,04$ ). There was nonsignificant reduction in mortality at 28 days (39\% vs. $21 \%$ ).

This issue of "Medicina Intensiva" journal (9), presents a post-hoc analysis of this study which included patients with severe ARDS according to Berlin consensus conference criteria, reporting that in severe ARDS patients, they found more organ dysfunctionfree days at 28 days $(12.83 \pm 10.70$ vs. $3.09 \pm 7.23, p=0.04)$ and a trend toward lower 28 days mortality when PEEP was applied according to best static compliance $(33.3 \%$ vs. $72.7 \%, p=0.16)$. In patients with moderate ARDS, they did not find those effects. An important limitation of this study is the sample size, this could explain some of the negatives results. I

A very interesting finding of this study is that patients randomized to compliance-guided PEEP adjustment group had a strong trend to lower driving pressure mainly at the beginning of the evolution of the disease. This finding was very similar regardless of severity of ARDS. Recently, Amato et all (10) performed a multilevel mediation analysis with nine previous randomized trials on patients with ARDS to examine if the driving pressure (VT/ respiratory-system compliance) was an independent variable associated with survival.

The authors of the study declare its limitations, originated mainly its post-hoc analysis of a randomized trial with a low number of patients, however it is useful to create a hypothesis of great interest to justify conducting a multicenter clinical trial to resolve definitely the important question "What PEEP level should I use in my patient?", meanwhile, from the respiration physiology perspective, PEEP optimization based on 
clinical situation and lung mechanics in each individual case might be the best option, perhaps making use of bedside imaging techniques as ultrasound or electrical impedance tomography (FIGURE 1), although it is not the easiest one at the routine clinical practice.

As we have seen in PROSEVA study (11) regarding the use of prone-position during ventilation, the biggest benefit of this physiologic approach might lie in its specific use in high risk patients who need an individualized treatment (12).

\section{REFERENCES:}

(1) Bellani G, Laffey JG, Pham T, Fan E, Brochard L, Esteban A, et al. Epidemiology, Patterns of Care, and Mortality for Patients With Acute Respiratory Distress Syndrome in Intensive Care Units in 50 Countries. JAMA 2016;315:788-800.

(2) The National Heart, Lung, and Blood Institute ARDS Clinical Trials Network. Higher versus Lower Positive End-Expiratory Pressures in Patients with the Acute Respiratory Distress Syndrome. N Engl J Med 2004; 351:327-36

(3) Blanch L, Villagra A, Sales B, Montanya J, Lucangelo U, Luján M, et al. Asynchronies during mechanical ventilation are associated with mortality. Intensive Care Med. 2015;41:633-41.

(4) The Acute Respiratory Distress Syndrome Network Ventilation with lower tidal volumes as compared with traditional tidal volumes for acute lung injury and the acute respiratory distress syndrome. N.Engl.J.Med. 2000; 342: 1301-8

(5) Cardinal-Fernández P, Correger E, Villanueva J y Rios F. Distrés respiratorio agudo: del síndrome a la enfermedad. Med Intensiva. 2016;40:169-75

(6) Gattinoni L, Carlesso E, Brazzi L, Caironi P. Positive end-expiratory pressure. CurrOpinCrit Care 2010; 16: 39-44.

(7) Gordo-Vidal F, Gómez-Tello V, Palencia-Herrejón E, Latour-Pérez J, Sánchez-Artola B, y Díaz-Alers R. PEEP alta frente a PEEP convencional en el síndrome de distrés respiratorio agudo Revisión sistemática y metaanálisis. Med Intensiva 2007;31:491-501.

(8) Pintado MC, de Pablo R, Trascasa M, Milicua JM, Rogero S, Daguerre M, et al. Individualized positive end-expiratory pressure setting in patients with Acute Respiratory Distress Syndrome. A randomized controlled pilot study. Respir Care 2013; 58: 1416-23. 
(9) Pintado MC, de Pablor R, Trascasa M, Milicua JM y Sánchez-García M. Complianceguided versus FiO2-driven positive-end expiratory pressure in patients with moderate or severe acute respiratory distress syndrome according to Berlin definition. Med Intensiva. In Press.

(10) Amato M, Meade M, Slutsky A, Brochard L, Costa EL, Schoenfeld DA et al. Driving Pressure and Survival in the Acute Respiratory Distress Syndrome. N Engl J Med 2015; 372:747-55

(11) Prone Positioning in Severe Acute Respiratory Distress Syndrome. N Engl J Med 2013. 368;23:20159-68

(12) Gordo F y Hermosa C. Fisiología y evidencia se unen en favor de la posición de decúbito prono. Med Intensiva.2015;39:327-8 